\title{
The Impact of Genetics and Other Factors on Intra- and Post-partum Pain
}

\author{
Ruth Landau • Clemens M. Ortner • \\ Pascal H. Vuilleumier
}

Published online: 10 August 2013

(C) Springer Science+Business Media New York 2013

\begin{abstract}
In an attempt to provide some explanation for the observed differences in pain perception and analgesic requirements during labor and delivery between women, the idea that genetic variability is an important factor has emerged over the past decade. Bearing in mind the challenges posed when evaluating pain during childbirth as a phenotype, recent findings in the field of genetics and obstetric anesthesia are presented in this review; in particular those related to differences in labor analgesia requirements between women, the response to opioids after cesarean delivery, as well as theories on why post-cesarean pain may be different from other types of post-surgical pain.
\end{abstract}

Keywords Labor pain - Cesarean delivery ·

Genetics · Polymorphism · Opioid · OPRM1

\section{Introduction}

Recent developments in genetic research have opened vast opportunities to expand and improve our understanding of how genetic variability impacts disease severity, and how pharmacogenomics has the potential to transform the way medicine is provided to offer individualized personalized care. Successful implementation of pharmacogenomics discoveries has already occurred in various medical disciplines, resulting in reduced side effects and improved drug

R. Landau $(\bowtie) \cdot$ C. M. Ortner · P. H. Vuilleumier Department of Anesthesiology and Pain Medicine, University of Washington Medical Center, 1959 NE Pacific

Street, Suite BB 1415B, Seattle, WA 98195, USA

e-mail: rulandau@u.washington.edu efficacy with cancer therapies, psychotropic agents and management of cardiovascular diseases.

Can these successes also be introduced in the field of obstetric anesthesia in order to improve our daily care of laboring women and provide tailored labor analgesia? In an attempt to provide some explanation for the observed differences in pain perception and analgesic requirements during labor and delivery between women, the idea that genetic variability may be an important factor has emerged in the past decade. If certain women are able to tolerate labor pain and 'resist' the temptation of a labor epidural, it may well be that they have a different genetic make-up that helps them endure childbirth pain or that certain genes improve the efficacy and analgesic response to pharmacological interventions.

Childbirth is one of the most desired event in many couple's life and over 4 million deliveries are celebrated every year in the United States [1]. Therefore, the expectation that studying intra- and post-partum pain will be easy, feasible and straightforward is realistic. However, it is not uncommon nowadays for women to prepare a 'birth plan' with specific requests based on beliefs and expectations that often include a 'natural childbirth'. 'Natural childbirth' probably means different things to different women. Often considered to represent a vaginal as opposed to a cesarean delivery, for some women "natural childbirth" implies a 'non-medicated childbirth' or simply 'having a baby without an epidural'. This remains a perplexing observation for the well intended obstetric anesthesiologist that so many women prefer to suffer the 'worst pain they will endure in their lifetime' without enjoying the benefits of what we can so easily provide and consider to be safe: effective, low dose neuraxial analgesia [2]. It is even more surprising to find out that women who end up with a cesarean delivery, whether having first been in labor 
or not, report high pain scores and take non-trivial amounts of opioids for pain relief [3]. It is almost as if pain during the numerous and unpredictable (long) hours of labor followed by that during vaginal delivery was a desirable and tolerable type of pain that required no analgesics whatsoever, whereas that occurring after a relatively simple surgical procedure was unbearable and resulted in severe pain for most women despite multimodal analgesia.

Obviously, labor pain and post-cesarean pain represent two very distinct pain entities: labor representing the ultimate visceral and mechanical model of acute pain, while the somatic pain, pulling, tugging and stretching that typically occurs during cesarean delivery represents a surgical model of acute pain with potential chronic neuropathic features. Perhaps one should reconsider the entire question. Perhaps post-cesarean pain is very different from any other post-surgical pain, because women have different expectations, because their hormonal status is unique, and because analgesia until recently has been quite minimal due to concerns surrounding analgesia in breastfeeding mothers. Interestingly, very few studies have evaluated whether labor pain followed by a cesarean delivery actually increased post-cesarean pain and analgesic requirements, due to the combination of an incision superimposed on a 'struggling' laboring uterus, to the fatigue that often results from undergoing labor followed by a cesarean delivery and to the disappointment of not being able to deliver 'naturally' as planned.

One can only agree that the subjective 'phenomenological' context of childbirth, along with psychosocial, demographic and obstetrical factors result in labor pain being one of the most challenging phenotype to evaluate, quantify, compare and interpret. In most pain studies evaluating clinical pain, a numerical pain scale is used to score the intensity of pain, and the amount of pain medication required to manage pain is another crucial outcome. How can we measure pain when most women believe that labor pain should be untreated, and why have we believed for so long that we could capture the essence of labor pain and quantify its severity by asking women to rate their pain during contractions over hours on a scale from 'no pain' to the 'worst imaginable' when labor pain is so experiential?

Bearing in mind the challenges posed when evaluating pain during childbirth as a phenotype, recent findings in the field of genetics and obstetric anesthesia such as differences in labor analgesia requirements between women, the response to opioids after cesarean delivery and theories on why post-cesarean pain may be different from other types of post-surgical pain will be presented in this review. We will explore the exciting hypothesis that has recently emerged regarding the protective effect that central oxytocin may have on post-cesarean pain, resulting in a longterm protection from chronic pain after cesarean delivery.

\section{Impact of Genetics on Labor Pain}

Less than a handful of genes have so far been evaluated in the context of labor pain and analgesic response to systemic or neuraxial opioids; the two most well studied genes are the $\mu$-opioid receptor gene (OPRM1) and the catechol$O$-methyltransferase gene (COMT) gene (Tables 1 and 2).

\section{The $\mu$-Opioid Receptor Gene (OPRM1)}

Despite numerous studies in the last two decades, the exact mechanism by which the most common and well studied polymorphism of OPRM1 (A118G, p.40Asn/Asp) influences opioid analgesia remains unresolved and the relevance of this genetic variant for the clinician is somewhat unclear [4-6]. Nonetheless, recent findings suggest that the altered $\mu$-opioid receptor may be associated with an enhanced effect in response to endogenous opioids, but a decreased response to exogenous opioids. In other words, individuals, carrying the G118 allele, should have a higher threshold to pain (due to increased sensitivity to endogenous opioids), but may require higher doses of $\mu$-opioid agonists to achieve analgesia, and be at higher risk for opioid-induced side effects.

Factors that have made various studies difficult to interpret and findings difficult to generalize include sexgenotype interactions [7] and a large inter-ethnic variability in genotype distribution [8] with an ethnicity-dependent association of OPRM1 genotype with pain sensitivity [9•].

\section{OPRM1 and Labor Pain}

In a large retrospective observational study in a cohort of Swedish women $(n=814)$, enrolled over a period of three months, there was no association between A118G genotype and labor pain related behaviors [10]. The phenotype that was evaluated was composed of the following factors: (1) the cervical exam upon arrival in the labor room, and (2) the use of any type of analgesia (acupuncture, nitrous oxide, systemic opioids, epidural). In other terms, women did not seem to have different thresholds for labor pain or epidural request based on A118G genotype. Unfortunately, the response to labor analgesia in the form of systemic or epidural opioids was not evaluated, epidurals were placed at a relatively advanced stage in labor (6 $\mathrm{cm}$ of cervical dilatation), and the epidural rate was remarkably low $(30 \%)$, likely reflecting the institutional practice and overall national trends in obstetric anesthesia use. Therefore, the resulting lack of difference in epidural use between genetic groups is most likely the consequence of an overall low epidural rate and does not provide truly meaningful information with regards to genetic influences. Of note, the same investigators were also unable able to 
Table 1 Genotype frequency of SNPs of interest for labor analgesia and post-cesarean pain

\begin{tabular}{|c|c|c|c|c|c|}
\hline \multirow[t]{2}{*}{ Gene } & \multirow[t]{2}{*}{ Nucleotide } & \multirow[t]{2}{*}{ Polymorphism } & \multicolumn{3}{|c|}{ Genotype frequency by ethnicity } \\
\hline & & & Caucasian & African-American & Asian \\
\hline OPRM1 & c. $118 \mathrm{~A} / \mathrm{G}$ & rs1799971-p.40Asn/Asp & $\begin{array}{l}\text { AA } 65-70 \% \text { [8] } \\
\text { AG } 25-30 \% \\
\text { GG } 0-5 \%\end{array}$ & $\begin{array}{l}\mathrm{AA}=100 \%[22] \\
\mathrm{AG}=0 \\
\mathrm{GG}=0\end{array}$ & $\begin{array}{l}\mathrm{AA}=35 \%[24] \\
\mathrm{AG}=45 \% \\
\mathrm{GG}=20 \%\end{array}$ \\
\hline COMT & c. $472 \mathrm{G} / \mathrm{A}$ & rs4680—p.158Val/Met & $\begin{aligned} \mathrm{GG} & =22 \%[19] \\
\mathrm{GA} & =47 \% \\
\mathrm{AA} & =31 \%\end{aligned}$ & $\begin{aligned} \mathrm{GG} & =52 \%[87] \\
\mathrm{GA} & =44 \% \\
\mathrm{AA} & =4 \%\end{aligned}$ & $\begin{aligned} \mathrm{GG} & =62 \%[88] \\
\mathrm{GA} & =32 \% \\
\mathrm{AA} & =5 \%\end{aligned}$ \\
\hline$C Y P 2 D 6$ & & $\begin{array}{l}80 \text { SNPs affecting enzymatic activity } \\
\text { CYP2D6*1-normal } \\
\text { CYP2D6*2-increased } \\
\text { CYP2D6*3, *4, *5-none } \\
\text { CYP2D6 } * 9, * 10, * 17 \text {-decreased }\end{array}$ & $\begin{array}{l}\mathrm{UM}=5-10 \% \\
\mathrm{EM}=65-80 \% \\
\mathrm{IM}=10-15 \% \\
\mathrm{PM}=5-10 \%\end{array}$ & $\begin{array}{l}\mathrm{UM}=40 \% \\
\mathrm{EM}=50 \% \\
\mathrm{IM}=9 \% \\
\mathrm{PM}=1 \%\end{array}$ & $\begin{array}{l}\mathrm{UM}=2-5 \% \\
\mathrm{EM}=90 \% \\
\mathrm{IM}=5 \% \\
\mathrm{PM}=2-5 \%\end{array}$ \\
\hline$A B C B 1$ & c. $3435 \mathrm{C} / \mathrm{T}$ & rs1046542—synonymous p.1145Ile & $\begin{array}{l}\mathrm{CC}=24 \%[89] \\
\mathrm{CT}=48 \% \\
\mathrm{TT}=28 \%\end{array}$ & $\begin{array}{l}\mathrm{CC}=68 \%[89] \\
\mathrm{CT}=31 \% \\
\mathrm{TT}=1 \%\end{array}$ & $\begin{array}{l}\mathrm{CC}=31 \%[52] \\
\mathrm{CT}=51 \% \\
\mathrm{TT}=18 \%\end{array}$ \\
\hline
\end{tabular}

$U M$ Ultra-rapid metabolizer

EM Extensive metabolizer

$I M$ Intermediate metabolizer

$P M$ Poor metabolizer

SNP Single nucleotide polymorphism

$r s$ RefSNP

OPRM1 $\mu$-opioid receptor gene

COMT Catechol-O-methyltransferase gene

CYP2D6 Cytochrome P450 2D6

$A B C B 1$ ATP binding cassette sub-family $\mathrm{B}$ member 1 gene

find an association with a pain-protective haplotype of the guanosine triphosphate cyclohydrolase gene (GCHI) evaluating the same phenotype and labor pain related behaviors in their cohort of laboring women [11].

\section{OPRM1 and Intravenous Fentanyl for Labor Analgesia}

While the influence of A118G genotype on intravenous (IV) fentanyl has been evaluated in several studies mostly in Asian patients in the context of post-operative analgesia [12-18], only one study examined its effect for early labor analgesia [19]. However, fentanyl is often offered in North America to women in early labor in an effort to delay or avoid receiving neuraxial analgesia. Studying the influence of A118G genotype in this clinical context offers the potential to explore and compare the analgesic response to both IV and spinal fentanyl in the same woman under the same clinical conditions (i.e., labor pain).

In this North-American cohort $(n=98)$, most of whom were Caucasian, IV analgesic success was found to be relatively low; only $20 \%$ of women reported a pain score of less than 10/100 at 15 min after dosing [19]. A118G genotype in combination with p.158Val/Met (c.472G/A) of
COMT seemed to have an impact on the analgesic outcome. Specifically, IV fentanyl was least effective in women with the A/A-Met/Met combination of OPRMI and COMT, which was carried by $18 \%$ of women in this cohort. The study was not sufficiently powered to explore the hypothesis that spinal and systemic opioid dynamics are different and to determine whether enhanced analgesia in response to spinal fentanyl in the presence of the variant G118 allele might exist when an enhanced response to IV fentanyl did not.

\section{OPRM1 and Spinal Fentanyl for Labor Analgesia}

Three studies have evaluated the influence of A118G genotype on the response to spinal fentanyl given as part of a CSE analgesic for labor analgesia [20•, 21, 22].

The first was conducted in a Swiss cohort of nulliparous women $(n=224)$ requesting neuraxial analgesia early in labor [20*]. Using the up-down sequential allocation method, women carrying the G118 allele were shown to require substantially lower doses of spinal fentanyl than women without this allele. This finding was replicated with a different pharmacological study design using 
Table 2 Clinical effects of genetic variants in the context of labor pain, labor analgesia response and post-cesarean pain

\begin{tabular}{|c|c|c|c|c|}
\hline Genetic variant & Clinical context & Intervention & Outcome & \\
\hline OPRM1 A118G & Labor analgesia $(\mathrm{CSE})(N=224$, Swiss $)$ & $\begin{array}{r}\text { Spinal fentanyl } \\
(2.5-30 \mathrm{mcg})\end{array}$ & $\begin{array}{l}\text { Analgesia requested at greater cervical dilatation } \\
\text { Lower ED50 (1.5- to 2-fold) in women with G118 } \\
\text { allele }\end{array}$ & {$\left[20^{\bullet}\right]$} \\
\hline OPRM1 A118G & $\begin{array}{l}\text { Labor analgesia }(\mathrm{CSE})(N=190, \text { North } \\
\text { American) }\end{array}$ & Spinal fentanyl (25 mcg) & No effect of G118 on duration of spinal analgesia & [21] \\
\hline OPRM1 A118G & $\begin{array}{l}\text { Labor analgesia (IV) }(N=98, \text { North } \\
\text { American) }\end{array}$ & IV fentanyl $(1.5 \mathrm{mg} / \mathrm{kg})$ & $\begin{array}{l}\text { Study underpowered } \\
\text { Joined allelic effect (least effective in A118- } \\
\text { Met158 homozygotes) }\end{array}$ & [19] \\
\hline $\begin{array}{l}\text { COMT } \\
\quad \text { Val158Met }\end{array}$ & $\begin{array}{l}\text { Labor analgesia (IV) }(N=98 \text {, North } \\
\text { American) }\end{array}$ & IV fentanyl $(1.5 \mathrm{mg} / \mathrm{kg})$ & Less effective in Met158 homozygous women & [19] \\
\hline OPRM1 A118G & $\begin{array}{l}\text { Labor analgesia (Epidural) }(N=57 \text {, } \\
\text { Italian) }\end{array}$ & $\begin{array}{l}\text { Epidural sufentanil } \\
\quad(16-27 \mathrm{mcg})\end{array}$ & Lower ED50 in women with G118 allele & [23] \\
\hline OPRM1 A118G & $\begin{array}{l}\text { Labor pain and progress }(N=65 \text {, North } \\
\text { American) }\end{array}$ & NONMEM analysis & Underpowered (also for experimental pain) & [49] \\
\hline OPRM1 A118G & Labor pain $(N=814$, Swedish $)$ & Analgesia (all types) & $\begin{array}{l}\text { No difference in 'labor pain behaviors': } \\
\text { Similar cervical dilatation upon arrival in labor } \\
\text { room } \\
\text { Similar epidural rate (in the order of } 30 \% \text { ) }\end{array}$ & [10] \\
\hline OPRM1 A118G & $\begin{array}{l}\text { Cesarean pain }(N=103 \text {, North } \\
\text { American) }\end{array}$ & Spinal morphine $(150 \mathrm{mcg})$ & $\begin{array}{l}\text { No effect of G118 on breakthrough pain and } \\
\text { additional analgesics }\end{array}$ & [21] \\
\hline OPRM1 A118G & Cesarean pain $(N=588$, Chinese $)$ & $\begin{array}{l}\text { Spinal/IV morphine } \\
\quad(100 \mathrm{mcg})\end{array}$ & $\begin{array}{l}\text { Higher pain scores with G118 allele } \\
\text { Higher morphine dose (IV PCA) with G118 allele in } \\
\text { the } 1 \text { st } 24 \text { h (after spinal morphine) }\end{array}$ & [24] \\
\hline OPRM1 A118G & $\begin{array}{l}\text { Cesarean pain }(N=617 \text { Chinese; } \\
N=241 \text { Malay } ;=136 \text { Indian })\end{array}$ & $\begin{array}{l}\text { Spinal/IV morphine } \\
\quad(100 \mathrm{mcg})\end{array}$ & $\begin{array}{l}\text { G118 homozygosity more frequent among Malay } \\
\text { and Indian } \\
\text { Multiple regression analysis showed pain scores } \\
\text { predicted morphine dose, followed by ethnicity } \\
\text { and A118G genotype } \\
\text { Higher pain scores and morphine dose (IV PCA) } \\
\text { among Indians in the } 1 \text { st } 24 \text { h (after spinal } \\
\text { morphine) }\end{array}$ & [25] \\
\hline OPRM1 A118G & $\begin{array}{l}\text { Cesarean pain }(N=158, \text { North } \\
\text { American) }\end{array}$ & Hydrocodone & $\begin{array}{l}\text { No effect on pain, side effects or hydrocodone dose } \\
\text { Regression analysis showed that serum } \\
\text { hydromorphone levels were correlated with } \\
\text { enhanced analgesia, but only with A118 } \\
\text { homozygosity }\end{array}$ & {$[50]$} \\
\hline CYP2D6 & $\begin{array}{l}\text { Cesarean pain }(N=45 \text {, North } \\
\text { American) }\end{array}$ & Codeine & $\begin{array}{l}\text { Study underpowered } \\
\text { PM }(N=2) \text { no analgesia } \\
\text { UM }(N=3) \text { severe side effects }\end{array}$ & [51] \\
\hline$A B C B 1 \mathrm{C} 3435 \mathrm{~T}$ & Cesarean pain $(N=620$, Chinese $)$ & $\begin{array}{l}\text { Spinal/IV morphine } \\
\quad(100 \mathrm{mcg})\end{array}$ & $\begin{array}{l}\text { No difference in morphine dose (IV PCA) in the 1st } \\
24 \mathrm{~h} \text { (after spinal morphine) } \\
\text { Trend for higher incidence of persistent pain in TT } \\
\text { women and significantly longer duration of pain }\end{array}$ & {$[52]$} \\
\hline
\end{tabular}

CSE combined spinal-epidural

$I V$ intravenous

ED50 median effective dose (dose effective in $50 \%$ of women)

NONMEM nonlinear mixed effects modeling

$P M$ Poor metabolizer

$U M$ Ultra-rapid metabolizer

OPRM1 $\mu$-opioid receptor gene

COMT Catechol- $O$-methyltransferase gene

CYP2D6 Cytochrome P450 2D6

$A B C B 1$ ATP binding cassette sub-family B member 1 gene 
random-dose allocation, confirming a twofold difference in spinal fentanyl requirement between genetic groups. Of note, cervical dilatation at the time of analgesia request was significantly less in the 118 AA women than that in women carrying one or two variant alleles (118 AG or $118 \mathrm{GG})$. The finding of lower analgesic requirements at a more advanced stage in labor is consistent with the principle that women carrying the $G 118$ allele may have higher pain tolerance that allows them to wait longer before requesting neuraxial analgesia.

In a 2nd study performed in a North American cohort of laboring women $(n=190)$, time from a spinal dose of fentanyl $(25 \mathrm{mcg})$ until women requested additional analgesia was not influenced by A118G genotype [21], suggesting that this SNP may well influence spinal fentanyl potency without affecting the duration of analgesic action.

In the 3rd and most recent study, combining two ethnically distinct hospital centers [one from Israel $(N=45$; mixed Jew/Arab) and one from the United States $(N=80$; mixed Hispanic/African-American)], time from a spinal dose of fentanyl $(20 \mathrm{mcg})$ until request for additional analgesia was not influenced by A118G genotype, nor did the onset of analgesia or the occurrence of itching differ between genetic groups [22]. The major difference was the duration of analgesia and the percent of women itching that was found when comparing women from different recruitment centers, highlighting the importance of ethnicity and cultural differences in pain outcomes.

\section{OPRM1 and Epidural Sufentanil for Labor Analgesia}

In an observational study evaluating a cohort of Italian nulliparous women $(n=57)$ using the same up-down methodology, women carrying the G118 allele had a significantly lower dose requirement (ED50) for epidural sufentanil. These data demonstrated a similar pharmacogenetic association of A118G genotype with neuraxial opioid potency during labor analgesia, although with a more modest clinical effect [23].

Of importance, these findings of a pharmacogenetic effect of A118G on spinal fentanyl or epidural sufentanil, with lower dose requirements in laboring women with the G118 allele, are in disagreement with most if not all other studies examining the influence of $\mathrm{A} 118 \mathrm{G}$ genotype and opioid analgesia [6], whether one evaluates post-operative IV fentanyl consumption [12-18], spinal morphine for post-cesarean pain [21, 24, 25], IV morphine for postoperative pain [26-31] or oral morphine for chronic cancer pain $[5,32,33]$.

Potential explanations for such discrepant results are that the physiology of and pathways triggered by labor pain are remarkably different from pathways triggered during experimental, post-operative or chronic pain. Indeed, similar disparate results in human genetic studies of pain sensitivity have been shown to occur with other polymorphisms commonly assessed in pain studies [34]. Another potential explanation is that each opioid is affected differently and or that the response to systemic rather than spinal fentanyl is affected differently by OPRM1 genotype. Lastly, a recent study evaluating the response to different experimental modalities in healthy individuals found no significant effect of OPRM1 genotype on pain sensitivity in the overall sample, but when each ethnic group was examined separately (Caucasians, Hispanics and African-Americans), lower pain sensitivity was found among Caucasians carrying the G118 allele, with a trend in the opposite direction among Hispanics and no measurable effect among African-Americans (the $G$ allele is under-represented in this ethnicity) [9]. As there were no Asians in that study and the G118 allele is extremely common among Asians, studies comparing pain sensitivity and opioid response between Caucasians and Asians will be of added value. Also, it remains to be determined whether haplotype structure, gene-gene interactions, or DNA methylation [35], rather then the A118G genotype itself, are key to explain these inter-ethnic differences. Nonetheless, this ethnicity-dependent genetic association may contribute to some of the discrepancies reported in clinical studies as discussed above.

\section{The Catechol- $O$-methyltransferase Gene (COMT)}

The most well studied genetic variant of COMT is the p.158Val/Met (c.472G/A), which has been associated with pain sensitivity and various pain phenotypes. COMT regulates the metabolism of dopamine and noradrenaline, and high COMT activity as is the case with the Val158 allele, is associated with improved dopaminergic transmission and confers an advantage in the processing of aversive stimuli or stressful conditions (warrior strategy). The Met158 allele is associated with an advantage in memory and attention tasks (worrier strategy) [36]. Individuals homozygous for the Met158 allele display increased pain sensitivity but lower $\mu$-opioid system activation during sustained pain [34, 37, 38] and the Met158 allele has been associated with chronic pain disorders [39, 40], acute postoperative pain [29, 41], chronic post-surgical pain [42], and opioid-induced hyperalgesia (OIH) [43]. The effect of COMT genotype on pain processing seems to become apparent only when pain modulation is challenged, such as occurs after repeated pain stimulation [44], or after remifentanil exposure in healthy volunteers Met158 homozygous [43]. In a cohort of women with fibromyalgia, Met158 homozygotes displayed lower pressure pain thresholds and higher cold pain sensitivity [45]. 
COMT and Intravenous Fentanyl for Labor Analgesia

As previously mentioned in the study described above [19], A118G genotype of OPRM1 appeared to influence the analgesic outcome only in combination with the Val158Met genotype of COMT. Nonetheless, COMT genotype alone influenced the response to IV fentanyl; the average decrease in pain scores 15 min after a unique dose of IV fentanyl was lowest among women 158Met/Met (31\% of women) compared with that in women $158 \mathrm{Val} / \mathrm{Met}$ or $158 \mathrm{Val} / \mathrm{Val}$. While there is no doubt that IV fentanyl is not a common practice for labor analgesia, such findings may have useful clinical implications, such as not offering IV fentanyl in labor to women who will most likely not benefit from it.

These findings highlight the challenges in interpreting genetic association studies, in general, and in particular, when several SNPs are examined jointly [46, 47]. The major challenge remains to design studies with a crisp phenotype in the context of labor pain. [48]. Most existing studies seem to have been underpowered [19, 49], or to not have taken into account ethnic and cultural differences [22] or the impact of hospital and local practice [10].

\section{Impact of Genetics on Post-cesarean Pain and Analgesia}

Only a handful of clinical studies have examined the influence of pain genes on acute post-operative pain, opioid consumption and chronic pain and these have focused on the A118G genotype of OPRM1 [21, 24, 25, 50] (Table 2). Other candidate genes that have been examined in the context of cesarean deliveries include the response to codeine according to $C Y P 2 D 6$ genotype [51] and to acute and chronic pain after cesarean delivery according to ATPbinding cassette, sub-family $\mathrm{B}$ member 1 ( $A B C B 1$ ) genotype [52] (Table 2).

\section{OPRM1 and Post-cesarean Analgesia}

In Chinese women $(n=588)$ undergoing elective cesarean deliveries under spinal anesthesia (with morphine $100 \mathrm{mcg}$, no fentanyl), pain scores and IV PCA morphine use $24 \mathrm{~h}$ post-operatively were significantly lower in women A118 homozygous [24]. Distribution of IV morphine use over time (doses were recorded in $4 \mathrm{~h}$ time intervals) demonstrated that most of morphine use occurred during the first $4 \mathrm{~h}$ after spinal anesthesia. It is possible that this early IV morphine use reflects lack of analgesia upon arrival in the post-anesthesia care unit; indeed onset of analgesia procured by spinal morphine is known to be slow and can occur up to $45 \mathrm{~min}$ after its administration [53].
Consequently, initial differences in IV morphine use may be due to differences in pain perception rather than impaired spinal morphine analgesia in women carrying the G118 allele.

In a second report from the same institution, three different ethnic groups were evaluated $(n=617$ Chinese, $n=241$ Malays and $n=136$ Indians) [25]. There were significant differences in genotype distribution between ethnic groups (G118 homozygosity was more frequent among Malays and Indians than among Chinese women). The authors reported a large inter-individual range as 65 women did not take any IV morphine and the highest dose was $62 \mathrm{mg}$. Nonetheless, the average dose of self-administered morphine over $24 \mathrm{~h}$ was low $(<10 \mathrm{mg})$. In a multiple regression analysis, the most important factor contributing to morphine dose was maximum pain score, followed by ethnicity and A118G genotype. After correction for genotype, ethnicity was still a significant contributing factor, with Indian women reporting higher pain scores and using higher IV morphine doses.

A third study evaluated post-cesarean analgesia according to A118G genotype after a spinal dose of morphine $150 \mathrm{mcg}$ and fentanyl $15 \mathrm{mcg}$, in a cohort of North American women $(N=103)$ [21]. The study design was substantially different from the two previous studies conducted on Asian women, and, therefore, the findings are not comparable. Women were not given an IV PCA for morphine use, and there was no difference in the duration of spinal morphine analgesia (on average $22 \mathrm{~h}$ ) or need for analgesic supplementation over $72 \mathrm{~h}$ between genotypic groups. The incidence of nausea was similar between groups, however pruritus was less frequent in carriers of the G118 allele during the first $24 \mathrm{~h}$.

In a recent study, post-cesarean analgesia with oral hydrocodone was evaluated according to A118G genotype in a North American cohort $(n=158)$ [50]. This study was designed to compare analgesic and side effect profiles, according to A118G genotype, with quantitative serum opioid concentrations, as well as total opioid consumption. The potential role that hydromorphone, an opioid metabolite of hydrocodone, may play in the analgesic response to hydrocodone was also evaluated. The study has several limitations, including the fact that the clinical protocol was changed after the first 40 cases were enrolled (spinal morphine was added thereafter and post-operative pain regimen changed) and that 43 women had opioid not derived from hydrocodone that was detected in the serum samples (suggesting these patients violated the study protocol). There was no difference in pain scores or hydrocodone doses between genotypic groups, although regression analysis revealed that in women A118 homozygous but not those carrying the G118 allele, analgesia correlated with hydrocodone dose and serum hydromorphone 
but not hydrocodone levels. These results suggest that enhanced hydrocodone analgesia with A118 homozygosity is due to an enhanced response to its active metabolite, hydromorphone, rather than to a direct effect of A118G genotype on the response to hydrocodone. Since CYP2D6 genotype was not specifically examined, one cannot evaluate the combined effect of $\mathrm{A} 118 \mathrm{G}$ and CYP2D6 genotypes, or of a gene-gene interaction, nor can one extrapolate this finding to non-obstetric cohorts.

\section{CYP2D6 Genotype}

Cytochrome P450 enzymes (CYPs) play a major role, as these are responsible for about $80 \%$ of phase I metabolism, and CYP2D6 metabolizes approximately $25 \%$ of frequently used drugs. Individuals are classified as ultra-rapid (UM), extensive (EM), intermediate (IM) and poor (PM) metabolizers according to CYP2D6 activity, and there is a large variability in the frequency of UM and PM based on ethnicity [54]. Codeine was formerly commonly given for pain management after cesarean deliveries, as it is classified as a weak opioid by the World Health Organization (WHO), and as such was considered safe in the context of breastfeeding mothers. However, the death of a breastfed 13-day-old neonate following a morphine overdose because his mother, an UM, was taking codeine after childbirth [55] resulted in a recent FDA warning on codeine use in nursing mothers [56]. Indeed, toxic blood levels of morphine or its active metabolite morphine-6-glucuronide (M6G) may arise in mothers and neonates that are CYP2D6 UM or EM, because codeine is a pro-drug transformed by CYP2D6 into its active substance, morphine.

In addition, CYP2D6 induction, during pregnancy and the postpartum period, may impact the generation of active opioid metabolites such as morphine after the administration of codeine, or that of oxymorphone, $O$-desmethyltramadol and hydromorphone following oxycodone, tramadol, and hydrocodone, respectively [57].

Overall, the level of evidence linking gene variation (CYP2D6) to phenotype (increased biotransformation of codeine into morphine) is significant; however, there is no randomized clinical trial assessing the benefits of genetic testing prior to codeine therapy at large [58]. While failure of analgesia with codeine can be well predicted by genotyping alone in individuals that are PM, predicting extremely high morphine formation still requires the effort of combining genotyping with phenotyping [59]. Recently formed, the clinical pharmacogenetics implementation consortium (CPIC) [60••] has established clinical recommendations for drug dosing based on genetic testing for only eight different drugs to date. The prescription of codeine according to CYP2D6 genotype is one that may be relevant to the practice of obstetric anesthesia [61•].
CYP2D6 and Codeine for Post-cesarean Analgesia

In a recent pilot study in North American women $(n=45)$ receiving codeine for post-cesarean pain, analgesia according to CYP2D6 genotype was evaluated [51]. Only five patients carried extreme genotypes (two PMs and three UMs) and the study was overall underpowered. Nonetheless, as expected, codeine was ineffective in the two PMs and codeine related side-effects were noted in two out of three UMs.

Prediction of codeine toxicity in neonates and their mothers using maternal genetic markers is complex, and a recent study in a predominantly Caucasian cohort $(n=111)$ showed that $C Y P 2 D 6$ and $A B C B 1$ genotypes, but not that of $O P R M 1$ and COMT, were associated with codeine-induced CNS depression in neonates and their mothers [62]. However, because safer and more effective analgesic alternatives do exist, avoiding codeine in breastfeeding mothers is the current clinical recommendation [55, 63].

ATP-binding Cassette, Sub-family B Member 1 $(A B C B 1)$

The ATP-binding cassette B1 $(A B C B 1)$ gene encodes the efflux transporter P-glycoprotein (P-gp) which is a key determinant of the bioavailability of many opioids (i.e., fentanyl, sufentanil, alfentanil, morphine-6-glucuronide and morphine-3-glucuronide). P-gp is a drug efflux transporter that functions at the blood-brain-barrier to limit the availability of morphine in the central nervous system, and could potentially affect pain perception and the response to opioids.

There are few clinical studies to date evaluating the influence of $A B C B 1$ genotype on pain and opioid analgesia $[5,16,28,30,52,64,65]$. Most studies have not found $A B C B 1$ genotype to be associated with major differences in pain outcomes, although P-gp activity is reduced in individuals TT homozygous for the C3435T polymorphism resulting in higher morphine CSF concentration [66] and potentially lower morphine consumption.

\section{ABCB 1 and Post-cesarean Analgesia and Chronic Pain}

In a cohort of Chinese women $(n=620)$ undergoing an elective cesarean delivery with spinal anesthesia with morphine $100 \mathrm{mcg}$, pain scores and IV PCA morphine consumption was evaluated for $24 \mathrm{~h}$, and chronic pain was assessed with phone questionnaires up to six months postcesarean [52]. Three polymorphisms of $A B C B 1$ were evaluated: C1236T, G2677T/A and C3435T. Pain scores and morphine use for breakthrough pain were overall low. There was no difference in pain scores, IV PCA morphine dose, or incidence of side effects in the 1 st $24 \mathrm{~h}$ post-cesarean between genotypic groups. Among the 503 women that 
were followed up to six months post-cesarean, only 20 (4\%) had pain that lasted for longer than three months, and at six months, only $18(3.6 \%)$ reported still having pain at the site of the surgical incision. Women with the TT genotype of $\mathrm{C} 3435 \mathrm{~T}$ were more likely to report persistent pain after cesarean delivery (a nonsignificant trend) and duration of pain in these women was longest, of note, the C3435T genotype was carried by $18 \%$ of women.

\section{Chronic Pain After Cesarean Delivery}

The incidence of chronic pain after surgery has been shown to depend on the surgical procedure and to range between 4 and $50 \%$ [67]. The incidence of chronic pain after abdominal hysterectomy via Pfannenstiel is on the order of $10-15 \%[68,69]$, so one could anticipate that chronic pain after cesarean delivery would be in the same range, given the similarity of the procedure. However, recent prospective studies have identified that the incidence and severity of reported pain after cesarean delivery is remarkably low $[70 \bullet, 71 \bullet \bullet$, or quasi inexistent $[72 \bullet, 73]$.

Based mostly on retrospective surveys and a few prospective studies, risk factors for chronic pain post-partum include personal characteristics (e.g., genetic susceptibility), pre-operative factors (e.g., menstrual pain, chronic pain), intra-operative factors (e.g., length of incision, uterine exteriorization, general anesthesia) and post-operative factors (acute pain, postpartum depression).

Studies attempting to characterize the type of pain persisting after cesarean delivery have identified that it is mostly neuropathic [74] as is largely described for persistent post-surgical pain in the general population $[75,76]$. In addition, the presence of pre-operative scar hyperalgesia in women undergoing a repeat cesarean delivery predicts acute post-operative pain [77•] and may be associated with persistent pain.

\section{Role of Oxytocin in Preventing Chronic Pain After Cesarean Delivery}

One of the proposed mechanisms to explain the remarkably low incidence of chronic pain after cesarean delivery compared with that after other types of surgical procedures including hysterectomies, is that endogenous secretion of oxytocin during labor and delivery may confer protection.

Oxytocin is primarily synthesized in the paraventricular nucleus and the supraoptic nucleus of the hypothalamus. The paraventricular nucleus projects nerve fibers excreting oxytocin to various areas of the central nervous system including the spinal cord. In the spinal cord, nociceptive afferent messages originating from $\mathrm{C}$ and $\mathrm{A} \delta$ primary afferents are inhibited by a pathway that begins with oxytocin being released from the paraventricular nucleus, and exciting a subpopulation of glutamatergic interneurons in the most superficial layer of the dorsal horn projecting in the lamina I-II, which subsequently distribute their excitation to all GABAergic neurons. In numerous animal models, oxytocin has long been shown to possess antinociceptive effects [78-83]; intrathecal administration of oxytocin prevents long-term potentiation in the dorsal horn, thought to be an important mechanism of enhanced central pain processing.

Recent experiments in rats to examine the potential protective effect of oxytocin during pregnancy suggest that spinal oxytocin release in the postpartum period has a key role in reversing hypersensitivity secondary to nerve injury [84•]. Protection seems to occur if and when surgery is performed around the time of delivery, and becomes apparent in the postpartum period, suggesting that the oxytocinergic pathway may not influence labor pain per se. In addition, examining bulbospinal descending pathways, spinal cord glial activation, and proteins that are upregulated in the spinal cord in females only, multiple sites of protection from chronic pain have been identified, with sex-specific responses in the spinal cord glia which may confer protection from injury induced chronic pain during childbirth [85].

More research is needed to understand and substantiate the antihyperalgesic effects of endogenous oxytocin at the time of delivery and to examine the potential use of intrathecal oxytocin to reduce chronic post-surgical pain. In addition, the oxytocin system represents an extremely promising target for novel central nervous system drug development, and considerable research is evaluating the role that central oxytocin may have with the potential to treat a large array of brain disorders [86].

\section{Conclusions}

Evaluating labor pain, the response to labor analgesia, acute post-cesarean pain and pain that persists beyond the expected time of recovery after childbirth has proven to be complex and challenging. Finding relevant genetic associations in this clinical context is particularly complicated, because genotyping without robust phenotyping is meaningless.

Lessons learned from genomic studies in the field of pain are numerous. Pain is not a unique single entity; therefore, the impact of genetic variants may be different according to the pain model (experimental, labor, incisional, inflammatory, neuropathic) and the individuals being tested (sex, ethnicity, age, co-morbidities). Sexgenotype and ethnicity-dependent genetic interactions have been shown to exist, indicating that one cannot generalize findings from different cohorts and extrapolate from one study population to another. Lastly, severe pain does not 
necessarily predict higher analgesic requirements, because some genes increase pain sensitivity but at the same time enhance the response to opioids (e.g., COMT). There is currently no one single gene that can be associated with severe labor pain, or predict post-cesarean pain or chronic pain after childbirth. Pharmacogenetic studies have identified polymorphisms that influence the response to opioids and researchers are still in the process of evaluating the clinical relevance of such genetic associations. The only clinical recommendation that has been made based on pharmacogenetic testing is to avoid codeine in breastfeeding mothers unless it has been established that the mother is not an ultra-metabolizer for CYP2D6.

Finally, novel and exciting research is now focusing on the possible protective role of oxytocin in the development of chronic pain. Oxytocin, a hormone and neurotransmitter also known to influence social and emotional processing such as trust, bonding and empathy may not only reveal how psycho-social context might actually protect women from developing chronic pain after childbirth, but more importantly, provide one more clue in understanding the bio-psycho-social nature of pain.

In the meantime, standard tools and criteria to better define labor pain and persistent incapacitating pain need to be adapted to the obstetric population. Since cesarean deliveries constitute a unique surgical model and some women undergo multiple cesarean deliveries, over the course of several years, this offers the opportunity to perform longitudinal pain testing with robust pain phenotyping.

\section{Compliance with Ethics Guidelines}

Conflict of Interest Ruth Landau has received funding for research projects not related with the topic of this review from the Millennium Research Institute (Millennium Laboratories), and is the recipient of a Swiss National Foundation Research Grant (SNF \#3200B0-114129) that funded, in part, the OPRM1 genetic research conducted in Switzerland. Clemens M. Ortner and Pascal H. Vuilleumier declare that they have no conflicts of interest.

Human and Animal Rights and Informed Consent This article does not contain any studies with human or animal subjects performed by any of the authors.

\section{References}

Papers of particular interest, published recently, have been highlighted as:

- Of importance

•- Of major importance

1. Births and natality. http://wwwcdcgov/nchs/fastats/birthshtm. Accessed 22 July 2013.
2. Landau R, Ciliberto C. Modern labor analgesia. IASP Clin Updates. 2011;12(4):112-5.

3. Eisenach JC, Pan PH, Smiley R, Lavand'homme P, Landau R, Houle TT. Severity of acute pain after childbirth, but not type of delivery, predicts persistent pain and postpartum depression. Pain. 2008;140:87-94.

4. Mura E, Govoni S, Racchi M, et al. Consequences of the $118 \mathrm{~A}>\mathrm{G}$ polymorphism in the OPRM1 gene: translation from bench to bedside? J Pain Res. 2013;6:331-53.

5. Klepstad P, Fladvad T, Skorpen F, et al. Influence from genetic variability on opioid use for cancer pain: a European genetic association study of 2294 cancer pain patients. Pain. 2011;152: $1139-45$.

6. Walter C, Lotsch J. Meta-analysis of the relevance of the OPRM1 118A > G genetic variant for pain treatment. Pain. 2009;146: $270-5$.

7. Fillingim RB, Kaplan L, Staud R, et al. The A118G single nucleotide polymorphism of the mu-opioid receptor gene (OPRM1) is associated with pressure pain sensitivity in humans. J Pain. 2005;6:159-67.

8. Landau R, Cahana A, Smiley RM, Antonarakis SE, Blouin JL. Genetic variability of mu-opioid receptor in an obstetric population. Anesthesiology. 2004;100:1030-3.

9. - Hastie BA, Riley JL, III, Kaplan L, et al. Ethnicity interacts with the OPRM1 gene in experimental pain sensitivity. Pain 2012;153:1610-9. A recent study evaluating the response to different experimental modalities in healthy individuals; there was no significant effect of OPRM1 genotype on pain sensitivity in the entire sample, but when examining each ethnic group separately (Caucasians, Hispanics and African-Americans), a lower pain sensitivity was found among Caucasians carrying the G118 allele, while there was a trend in the opposite direction among Hispanics, no measurable effect among African-Americans (the $G$ allele is under-represented in this ethnicity), and there were no Asian women in that study. The reasons for this dichotomy are unclear; these findings demonstrate an ethnicitydependent association of OPRM1 genotype with pain sensitivity.

10. Pettersson FD, Gronbladh A, Nyberg F, Sundstrom-Poromaa I, Akerud H. The A118G single-nucleotide polymorphism of human mu-opioid receptor gene and use of labor analgesia. Reprod Sci. 2012;19:962-7.

11. Dabo F, Gronbladh A, Nyberg F, Sundstrom-Poromaa I, Akerud H. Different SNP combinations in the GCH1 gene and use of labor analgesia. Mol Pain. 2010;6:41.

12. Fukuda K, Hayashida M, Ide S, et al. Association between OPRM1 gene polymorphisms and fentanyl sensitivity in patients undergoing painful cosmetic surgery. Pain. 2009;147:194-201.

13. Wu WD, Wang Y, Fang YM, Zhou HY. Polymorphism of the micro-opioid receptor gene (OPRM1 118A > G) affects fentanylinduced analgesia during anesthesia and recovery. Mol Diagn Ther. 2009;13:331-7.

14. Zhang W, Chang YZ, Kan QC, et al. Association of human micro-opioid receptor gene polymorphism A118G with fentanyl analgesia consumption in Chinese gynaecological patients. Anaesthesia. 2010;65:130-5.

15. Zhang W, Yuan JJ, Kan QC, Zhang LR, Chang YZ, Wang ZY. Study of the OPRM1 A118G genetic polymorphism associated with postoperative nausea and vomiting induced by fentanyl intravenous analgesia. Minerva Anesthesiol. 2011;77:33-9.

16. Kim KM, Kim HS, Lim SH, et al. Effects of genetic polymorphisms of OPRM1, ABCB1, CYP3A4/5 on postoperative fentanyl consumption in Korean gynecologic patients. Int J Clin Pharmacol Ther. 2013;51:383-92.

17. Liao Q, Chen DJ, Zhang F, et al. Effect of CYP3A4*18B polymorphisms and interactions with OPRM1 A118G on postoperative 
fentanyl requirements in patients undergoing radical gastrectomy. Mol Med Rep. 2013;7:901-8.

18. Zhang F, Liao Q, Li L, et al. The correlation between postoperative fentanyl requirements and -opioid receptor gene A118G polymorphism in patients undergoing radical gastrectomy. Exp Ther Med. 2013;5:1147-52.

19. Landau R, Liu SK, Blouin JL, Carvalho B. The effect of OPRM1 and COMT genotypes on the analgesic response to intravenous fentanyl labor analgesia. Anesth Analg. 2013;116:386-91.

20. - Landau R, Kern C, Columb MO, Smiley RM, Blouin JL. Genetic variability of the mu-opioid receptor influences intrathecal fentanyl analgesia requirements in laboring women. Pain 2008;139:5-14. The first study in laboring women demonstrating a pharmacogenetic effect of OPRM1 genotype on the response to intrathecal fentanyl.

21. Wong CA, McCarthy RJ, Blouin J, Landau R. Observational study of the effect of mu-opioid receptor genetic polymorphism on intrathecal opioid labor analgesia and post-cesarean delivery analgesia. Int J Obstet Anesth. 2010;19:246-53.

22. Ginosar Y, Birnbach DJ, Shirov TT, Arheart K, Caraco Y, Davidson EM. Duration of analgesia and pruritus following intrathecal fentanyl for labour analgesia: no significant effect of A118G mu-opioid receptor polymorphism, but a marked effect of ethnically distinct hospital populations. Br J Anaesth. 2013.

23. Camorcia M, Capogna G, Stirparo S, Berritta C, Blouin JL, Landau R. Effect of mu-opioid receptor A118G polymorphism on the ED50 of epidural sufentanil for labor analgesia. Int J Obstet Anesth. 2012;21:40-4.

24. Sia AT, Lim Y, Lim EC, et al. A118G single nucleotide polymorphism of human mu-opioid receptor gene influences pain perception and patient-controlled intravenous morphine consumption after intrathecal morphine for postcesarean analgesia. Anesthesiology. 2008;109:520-6.

25. Tan EC, Lim EC, Teo YY, Lim Y, Law HY, Sia AT. Ethnicity and OPRM variant independently predict pain perception and patient-controlled analgesia usage for post-operative pain. Mol Pain. 2009;5:32.

26. Janicki PK, Schuler G, Francis D, et al. A genetic association study of the functional A118G polymorphism of the human muopioid receptor gene in patients with acute and chronic pain. Anesth Analg. 2006;103:1011-7.

27. Chou WY, Wang CH, Liu PH, Liu CC, Tseng CC, Jawan B. Human opioid receptor A118G polymorphism affects intravenous patient-controlled analgesia morphine consumption after total abdominal hysterectomy. Anesthesiology. 2006;105:334-7.

28. Coulbault L, Beaussier M, Verstuyft C, et al. Environmental and genetic factors associated with morphine response in the postoperative period. Clin Pharmacol Ther. 2006;79:316-24.

29. Kolesnikov Y, Gabovits B, Levin A, Voiko E, Veske A. Combined catechol- $O$-methyltransferase and mu-opioid receptor gene polymorphisms affect morphine postoperative analgesia and central side effects. Anesth Analg. 2011;112:448-53.

30. Mamie C, Rebsamen MC, Morris MA, Morabia A. First evidence of a polygenic susceptibility to pain in a pediatric cohort. Anesth Analg. 2013;116:170-7.

31. Sia AT, Lim Y, Lim EC, et al. Influence of mu-opioid receptor variant on morphine use and self-rated pain following abdominal hysterectomy. J Pain. 2013.

32. Klepstad P, Rakvag TT, Kaasa S, et al. The 118 A > G polymorphism in the human mu-opioid receptor gene may increase morphine requirements in patients with pain caused by malignant disease. Acta Anesthesiol Scand. 2004;48:1232-9.

33. Reyes-Gibby CC, Shete S, Rakvag T, et al. Exploring joint effects of genes and the clinical efficacy of morphine for cancer pain: OPRM1 and COMT gene. Pain. 2007;130:25-30.
34. Diatchenko L, Nackley AG, Slade GD, et al. Catechol- $O$-methyltransferase gene polymorphisms are associated with multiple pain-evoking stimuli. Pain. 2006;125:216-24.

35. Nielsen DA, Hamon S, Yuferov V, et al. Ethnic diversity of DNA methylation in the OPRM1 promoter region in lymphocytes of heroin addicts. Hum Genet. 2010;127:639-49.

36. Stein DJ, Newman TK, Savitz J, Ramesar R. Warriors versus worriers: the role of COMT gene variants. CNS Spectr. 2006;11:745-8.

37. Zubieta JK, Heitzeg MM, Smith YR, et al. COMT val158met genotype affects mu-opioid neurotransmitter responses to a pain stressor. Science. 2003;299:1240-3.

38. Andersen S, Skorpen F. Variation in the COMT gene: implications for pain perception and pain treatment. Pharmacogenomics. 2009;10:669-84.

39. Belfer I, Segall S. COMT genetic variants and pain. Drugs Today (Barc). 2011;47:457-67.

40. Tammimaki A, Mannisto PT. Catechol- $O$-methyltransferase gene polymorphism and chronic human pain: a systematic review and meta-analysis. Pharmacogenet Genomics. 2012;22:673-91.

41. Lee PJ, Delaney P, Keogh J, Sleeman D, Shorten GD. Catecholamine- $O$-methyltransferase polymorphisms are associated with postoperative pain intensity. Clin J Pain. 2011;27:93-101.

42. Hickey OT, Nugent NF, Burke SM, Hafeez P, Mudrakouski AL, Shorten GD. Persistent pain after mastectomy with reconstruction. J Clin Anesth. 2011;23:482-8.

43. Jensen KB, Lonsdorf TB, Schalling M, Kosek E, Ingvar M. Increased sensitivity to thermal pain following a single opiate dose is influenced by the COMT val(158)met polymorphism. PLoS One. 2009;4:e6016.

44. Loggia ML, Jensen K, Gollub RL, Wasan AD, Edwards RR, Kong J. The catechol- $O$-methyltransferase (COMT) val158met polymorphism affects brain responses to repeated painful stimuli. PLoS One. 2011;6:e27764.

45. Martinez-Jauand M, Sitges C, Rodriguez V, et al. Pain sensitivity in fibromyalgia is associated with catechol- $O$-methyltransferase (COMT) gene. Eur J Pain. 2013;17:16-27.

46. Landau R, Ortner C, Carvalho B. Challenges in interpreting joined allelic combinations of OPRM1 and COMT genes. Anesth Analg. 2011;113:432.

47. Landau R, Schwinn D. Genotyping without phenotyping: does it really matter? Anesth Analg. 2013;116:8-10.

48. Wong CA. The promise of pharmacogenetics in labor analgesia...tantalizing, but not there yet. Int J Obstet Anesth. 2012;21: $105-8$.

49. Reitman E, Conell-Price J, Evansmith J, et al. $\beta_{2}$-Adrenergic receptor genotype and other variables that contribute to labor pain and progress. Anesthesiology. 2011;114:927-39.

50. Boswell MV, Stauble ME, Loyd GE, et al. The role of hydromorphone and OPRM1 in postoperative pain relief with hydrocodone. Pain Phys. 2013;16:E227-35.

51. VanderVaart S, Berger H, Sistonen J, et al. CYP2D6 polymorphisms and codeine analgesia in postpartum pain management: a pilot study. Ther Drug Monit. 2011;33:425-32.

52. Sia AT, Sng BL, Lim EC, Law H, Tan EC. The influence of ATPbinding cassette sub-family $\mathrm{B}$ member-1 (ABCB1) genetic polymorphisms on acute and chronic pain after intrathecal morphine for caesarean section: a prospective cohort study. Int $\mathbf{J}$ Obstet Anesth. 2010;19:254-60.

53. Baraka A, Noueihid R, Hajj S. Intrathecal injection of morphine for obstetric analgesia. Anesthesiology. 1981;54:136-40.

54. Sistonen J, Sajantila A, Lao O, Corander J, Barbujani G, Fuselli S. CYP2D6 worldwide genetic variation shows high frequency of altered activity variants and no continental structure. Pharmacogenet Genomics. 2007;17:93-101. 
55. Koren G, Cairns J, Chitayat D, Gaedigk A, Leeder SJ. Pharmacogenetics of morphine poisoning in a breastfed neonate of a codeine-prescribed mother. Lancet. 2006;368:704.

56. FDA UFaDa. Public health advisory: use of codeine by some breastfeeding mothers may lead to life-threatening side effects in nursing babies. 2007.

57. Madadi P, Avard D, Koren G. Pharmacogenetics of opioids for the treatment of acute maternal pain during pregnancy and lactation. Curr Drug Metab. 2012;13:721-7.

58. Landau R, Bollag LA, Kraft JC. Pharmacogenetics and anaesthesia: the value of genetic profiling. Anaesthesia. 2012;67:165-79.

59. Lotsch J, Rohrbacher M, Schmidt H, Doehring A, Brockmoller J, Geisslinger G. Can extremely low or high morphine formation from codeine be predicted prior to therapy initiation? Pain. 2009;144:119-24.

60. •- Relling MV, Klein TE. CPIC: Clinical Pharmacogenetics Implementation Consortium of the Pharmacogenomics Research Network. Clin Pharmacol Ther. 2011; 89:387-91 Recently formed, the clinical pharmacogenetics implementation consortium (CPIC) has established clinical recommendations for dosing based on genetic testing for eight different drugs.

61. - Crews KR, Gaedigk A, Dunnenberger HM, et al. Clinical Pharmacogenetics Implementation Consortium (CPIC) guidelines for codeine therapy in the context of cytochrome P450 2D6 (CYP2D6) genotype. Clin Pharmacol Ther. 2012;91:321-6. One of the CPIC guidelines; codeine prescription according to CYP2D6 genotype may be the only guideline relevant to the practice of anesthesiologists, pain doctors, pediatricians, obstetricians or perinatologists.

62. Sistonen J, Madadi P, Ross CJ, et al. Prediction of codeine toxicity in infants and their mothers using a novel combination of maternal genetic markers. Clin Pharmacol Ther. 2012;91:692-9.

63. Madadi P, Moretti M, Djokanovic N, et al. Guidelines for maternal codeine use during breastfeeding. Can Fam Phys. 2009;55: 1077-8.

64. Campa D, Gioia A, Tomei A, Poli P, Barale R. Association of ABCB1/MDR1 and OPRM1 gene polymorphisms with morphine pain relief. Clin Pharmacol Ther. 2008;83:559-66.

65. Zwisler ST, Enggaard TP, Noehr-Jensen L, et al. The antinociceptive effect and adverse drug reactions of oxycodone in human experimental pain in relation to genetic variations in the OPRM1 and ABCB1 genes. Fundam Clin Pharmacol. 2010;24:517-24.

66. Meineke I, Freudenthaler S, Hofmann U, et al. Pharmacokinetic modelling of morphine, morphine-3-glucuronide and morphine6-glucuronide in plasma and cerebrospinal fluid of neurosurgical patients after short-term infusion of morphine. Br J Clin Pharmacol. 2002;54:592-603.

67. Kehlet H, Jensen TS, Woolf CJ. Persistent postsurgical pain: risk factors and prevention. Lancet. 2006;367:1618-25.

68. Brandsborg B, Nikolajsen L, Kehlet H, Jensen TS. Chronic pain after hysterectomy. Acta Anaesthesiol Scand. 2008;52:327-31.

69. Brandsborg B, Dueholm M, Nikolajsen L, Kehlet H, Jensen TS. A prospective study of risk factors for pain persisting 4 months after hysterectomy. Clin J Pain. 2009;25:263-8.

70. - Landau R, Bollag L, Ortner C. Chronic pain after childbirth. Int J Obstet Anesth. 2013;22:133-45. Reviews the evidence on the incidence, risk factors, predictors, and strategies to prevent acute pain after cesarean delivery and potentially chronic pain.

71. • Lavand'homme P. Chronic pain after childbirth. Curr Opin Anaesthesiol. 2013;26:273-7. Excellent review on the topic of chronic pain after cesarean and vaginal deliveries.

72. • Eisenach JC, Pan P, Smiley RM, Lavand'homme P, Landau R, Houle TT. Resolution of pain after childbirth. Anesthesiology. 2013;118:143-51. For the first time in a large prospective cohort of women delivering in the US, the incidence of chronic pain after delivery was extremely low $(<1 \%)$.
73. Flood P, Wong CA. Chronic pain secondary to childbirth: does it exist? Anesthesiology. 2013;118:16-8.

74. Loos MJ, Scheltinga MR, Mulders LG, Roumen RM. The Pfannenstiel incision as a source of chronic pain. Obstet Gynecol. 2008;111:839-46.

75. Johansen A, Romundstad L, Nielsen CS, Schirmer H, Stubhaug A. Persistent postsurgical pain in a general population: prevalence and predictors in the Tromso study. Pain. 2012;153:1390-6.

76. Haroutiunian S, Nikolajsen L, Finnerup NB, Jensen TS. The neuropathic component in persistent postsurgical pain: a systematic literature review. Pain. 2013;154:95-102.

77. • Ortner CM, Granot M, Richebe P, Cardoso M, Bollag L, Landau R. Preoperative scar hyperalgesia is associated with post-operative pain in women undergoing a repeat Caesarean delivery. Eur J Pain. 2013;17:111-23. In women undergoing an elective repeat cesarean delivery, mapping the scar pre-operatively with a Von Frey filament identified hypersensitization in $40 \%$ of women, and predicted severe acute pain post-cesarean delivery.

78. Millan MJ, Schmauss C, Millan MH, Herz A. Vasopressin and oxytocin in the rat spinal cord: analysis of their role in the control of nociception. Brain Res. 1984;309:384-8.

79. Condes-Lara M, Rojas-Piloni G, Martinez-Lorenzana G, Rodriguez-Jimenez J, Lopez Hidalgo M, Freund-Mercier MJ. Paraventricular hypothalamic influences on spinal nociceptive processing. Brain Res. 2006;1081:126-37.

80. Miranda-Cardenas Y, Rojas-Piloni G, Martinez-Lorenzana G, et al. Oxytocin and electrical stimulation of the paraventricular hypothalamic nucleus produce antinociceptive effects that are reversed by an oxytocin antagonist. Pain. 2006;122:182-9.

81. Breton JD, Veinante P, Uhl-Bronner S, et al. Oxytocin-induced antinociception in the spinal cord is mediated by a subpopulation of glutamatergic neurons in lamina I-II which amplify GABAergic inhibition. Mol Pain. 2008;4:19.

82. Condes-Lara M, Rojas-Piloni G, Martinez-Lorenzana G, LopezHidalgo M, Rodriguez-Jimenez J. Hypothalamospinal oxytocinergic antinociception is mediated by GABAergic and opiate neurons that reduce A-delta and $\mathrm{C}$ fiber primary afferent excitation of spinal cord cells. Brain Res. 2009;1247:38-49.

83. DeLaTorre S, Rojas-Piloni G, Martinez-Lorenzana G, RodriguezJimenez J, Villanueva L, Condes-Lara M. Paraventricular oxytocinergic hypothalamic prevention or interruption of long-term potentiation in dorsal horn nociceptive neurons: electrophysiological and behavioral evidence. Pain. 2009;144:320-8.

84. - Gutierrez S, Liu B, Hayashida K, Houle TT, Eisenach JC. Reversal of peripheral nerve injury-induced hypersensitivity in the postpartum period: role of spinal oxytocin. Anesthesiology. 2013;118:152-9. Experiments in rats to examine the potential protective effect of oxytocin during pregnancy suggest that spinal oxytocin release in the postpartum period has a key role in reversing hypersensitivity secondary to nerve injury.

85. Gutierrez S, Hayashida K, Eisenach JC. The puerperium alters spinal cord plasticity following peripheral nerve injury. Neuroscience. 2013;228:301-8.

86. Macdonald K, Feifel D. Helping oxytocin deliver: considerations in the development of oxytocin-based therapeutics for brain disorders. Front Neurosci. 2013;7:35.

87. Al-Hendy A, Salama SA. Catechol- $O$-methyltransferase polymorphism is associated with increased uterine leiomyoma risk in different ethnic groups. J Soc Gynecol Investig. 2006;13:136-44.

88. Liang S, Liu X, Fan P, et al. Association between Val158Met functional polymorphism in the COMT gene and risk of preeclampsia in a Chinese population. Arch Med Res. 2012;43: $154-8$.

89. Ameyaw MM, Regateiro F, Li T, et al. MDR1 pharmacogenetics: frequency of the C3435T mutation in exon 26 is significantly influenced by ethnicity. Pharmacogenetics. 2001;11:217-21. 